\title{
Pengembangan Media Pembelajaran Biologi Menggunakan Teknologi Augmented Reality (AR) Berbasis Android pada Konsep Sistem Saraf
}

\section{Development of Biology Learning Media Using Augmented Reality (AR) Technology Based Android in the Concept of Nervous Systems}

\author{
Ipin Aripin $^{1 *}$, Yeni Suryaningsih ${ }^{1)}$ \\ ${ }^{1}$ Pendidikan Biologi, Fakultas Keguruan dan Ilmu Pendidikan, Universitas Majalengka
}

Received $8^{\text {th }}$ August $2019 /$ Accepted $20^{\text {th }}$ August 2019

\begin{abstract}
ABSTRAK
Augmented Reality (AR) merupakan teknologi terkini yang dapat menjadi solusi bagi pendidik untuk menyajikan pembelajaran yang inovatif, informatif, menarik, dan dapat menyajikan objek maya secara virtual 3D dalam bentuk nyata serta disajikan secara real time (waktu nyata), sehingga mampu menyajikan konsep abstrak menjadi lebih nyata. Penelitian ini bertujuan untuk mengembangkan aplikasi pembelajaran Biologi menggunakan teknologi AR berbasis Android pada konsep sistem saraf yang layak dan efektif digunakan dalam pembelajaran Biologi. Metode penelitian pengembangan yang digunakan pada penelitian ini adalah model pengembangan menurut Akker dengan empat tahapan, yaitu tahapan penelitian pendahuluan (Preliminary Research), tahapan prototipe (Prototyping Stage), tahapan evaluasi sumatif (Summative Evaluation) serta refleksi sistematik dan dokumentasi (Systematic Reflection and Documentation). Instrumen penelitian yang digunakan terdiri atas tes (penguasaan konsep) dan non tes (lembar penilaian ahli, angket, dan wawancara).Data kemudian dianalisis secara kualitatif dan kuantitatif. Hasil penelitian menunjukkan bahwa media pembelajaran Biologi berbasis AR yang dikembangkan menurut penilaian ahli termasuk layak (valid) digunakan dengan ketegori sangat baik untuk aspek media, kategori baik untuk aspek konten, dan kategori sangat baik untuk aspek pedagogik. Berdasarkan hasil implementasi dalam pembelajaran Biologi media AR yang dikembangkan tergolong efektif dan dapat meningkatkan pencapaian ketuntasan belajar siswa sebesar $76 \%$.
\end{abstract}

Kata kunci: Pembelajaran Biologi, Augmented Reality, Android, Sistem Saraf

\begin{abstract}
Augmented Reality (AR) is the latest technology that can be a solution for educators to present learning that is innovative, informative, interesting, and can present virtual $3 D$ objects in real form and presented in real time, so as to be able to present abstract concepts become more real. This study aims to develop Biology learning applications using Android-based AR technology on the concept of a proper and effective nervous system used in Biology learning. The development research method used in this study is the development model according to Akker with four stages, namely the preliminary
\end{abstract}

*Korespondensi:

email: ipin.aripin@unma.ac.id/i.arifin85@gmail.com 
research stage, the prototype stage, the summative evaluation stage and the systematic reflection and documentation. The research instrument used consisted of tests (mastery of concepts) and non-tests (expert assessment sheets, questionnaires, and interviews). Data were then analyzed qualitatively and quantitatively. The results showed that AR-based Biology learning media developed according to expert judgment are considered valid with excellent categories for media aspects, good categories for content aspects, and very good categories for pedagogical aspects. Based on the results of implementation in learning the Biology of AR media developed is quite effective and can increase the achievement of students' mastery learning by $76 \%$.

Keywords: Learning Biology, Augmented Reality, Android, Nervous System.

\section{PENDAHULUAN}

Kemajuan ilmu pengetahuan dan teknologi, khususnya teknologi informasi, sangat berpengaruh terhadap penyusunan dan implementasi strategi pembelajaran.Melalui kemajuan tersebut para guru dapat menggunakan berbagai media sesuai dengan kebutuhan dan tujuan pembelajaran. Dengan penggunaan media bukan saja dapat mempermudah dan mengefektifkan proses pembelajaran, akan tetapi bisa membuat pembelajaran lebih menarik (Sanjaya, 2013). Proses pembelajaran merupakan merupakan proses komunikasi yang melibatkan tiga unsur pokok, yaitu guru sebagai pengirim pesan pembelajaran, siswa sebagai penerima pesan, dan pesan itu sendiri yang berbentuk materi pelajaran. Agar penyampaian pesan pembelajaran lebih efektif maka diperlukan sebuah alat bantu untuk memfasilitasi penyampaian tersebut pesan berupa media.

Saat ini penggunaan media pembelajaran di kalangan guru, khususnya yang berbasis teknologi informasi menunjukkan peningkatan yang signifikan. Penggunaan perangkat bergerak (mobile) dalam pembelajaran sudah menjadi sebuah kebutuhan dalam memfasilitasi proses belajar mengajar. Perangkat mobile seperti laptop, tablet, dan smartphone telah menjadi alternatif baru dalam pembelajaran yang menyajikan kemudahan pembelajaran karena dapat diakses kapan pun dan dimanapun (Sarrab, 2012; Aripin, 2018).Salah satu trend media pembelajaran yang mulai dilirik dalam dunia pendidikan adalah media dengan teknologi Augmented Reality (AR) berbasis Android.

AR menurut The New Media Corsortium dalam Vega (2017) sebagai penggabungan informasi digital termasuk model 3D, gambar, video, dan audio ke dalam ruang dunia nyata. AR bertujuan untuk memadukan realitas dengan lingkungan virtual, memungkinkan pengguna untuk berinteraksi dengan keduanya objek fisik dan digital. Dalam bidang pendidikan teknologi ini masih sedikit dikembangkan sehingga peluang untuk pengembangan media berbasis teknologi AR sangat terbuka lebar.

Teknologi AR yang dalam Bahasa Indonesia disebut sebagai realitas bertambah merupakan teknologi yang mampu menambahkan realitas di dunia nyata dengan objek virtual sehingga seolah tidak ada batas antara dunia nyata dengan dunia virtual.Menurut Wang (2017) AR merupakan teknologi yang menggabungkan lingkungan nyata dan objek virtual dengan berbantuan komputer. Teknologi AR merupakan pengembangan dari Virtual Reality (VR) yang memiliki konsep berbeda. Ketika VR menarik pengguna seakan masuk ke dalam lingkungan 3 dimensi, maka AR menambahkan realita yang ada dan nyata di dunia nyata dengan objek yang terangkat / ditambahkan (Augmented), dimana teknologi ini seakan menghilangkan dunia maya 3 dimensi, menyatu dengan dunia nyata (Azuma, 1997; Arifitama, 2017). Secara singkat AR menurut Azuma (1997) adalah teknologi yang mampu menggabungkan objek maya berupa dua dimensi maupun tiga dimensi ke dalam sebuah lingkungan nyata dan ditampilkan secara 
realtime (waktu nyata). Dalam bidang pendidikan teknologi ini masih sedikit dikembangkan sehingga peluang untuk pengembangan media berbasis teknologi AR sangat terbuka lebar.

Tujuan penggunaan teknologi ARadalah menambahkan pengertian dan informasi pada dunia nyata dimana sistem ARmengambil dunia nyata sebagai dasar dan menggabungkan beberapa teknologi dengan menambahkan data kontekstual agar pemahaman seseorang menjadi jelas (Azuma, 1997; Kamelia, 2015; Arifitama, 2017).Dalam pembelajaran biologi penggunaan AR bisa menampilkan visualisasi 3D yang dapat membantu siswa untuk memahami konsep-konsep biologi yang bersifat abstrak menjadi lebih nyata khususnya pada kajian tentang anatomi manusia seperti pada konsep sistem saraf.

Berdasarkan hasil wawancara dengan guru biologi dan siswa di SMAN I Kadipaten Kabupaten Majalengka, salah satu materi biologi yang berkaitan dengan anatomi manusia yang dianggap sulit oleh siswa adalah materi tentang sistem saraf, pada Kurtilas revisi kajian tentang sistem saraf merupakan bagian dari konsep sistem koordinasi yang meliputi sistem saraf, sistem endokrin dan sistem indera. Pada materi sistem saraf dipelajari tentang jenis sel saraf, mekanisme kerja saraf, otak, dan kelainan sistem saraf (Irnaningtyas, 2019).

Menurut Mulyani (2012) konsep sistem saraf memiliki karakteristik materi yang abstrak dan rumit salah satunya karena berhubungan dengan mekanisme fisika dan kimiawi yang kompleks. Mekanisme sebab akibat yang terdapat pada materi sistem saraf membuat siswa kesulitan memahami cara kerja dari sistem tersebut. Sistem saraf merupakan salah satu materi yang cukup penting dalam fisiologi hewan untuk memahami konsep-konsep selanjutnya (Mulyani, 2013). Karena sifatnya kompleks inilah materi sistem saraf perlu difasilitasi dengan penggunaan media 3D yang memudahkan siswa untuk memahaminya, yaitu melalui media berbasis Augmented Reality, untuk itu perlu dikembangkan sebuah media menggunakan teknologi AR yang memiliki kelayakan dari segi konten, kehandalan dan kemudahan dari segi penggunaannya serta kesesuaian dengan karakteristik siswa dan kurikulum 2013 revisi untuk mata pelajaran biologi. Sehingga pengembangan aplikasi pembelajaran biologi dengan teknologi AR yang dibuat dikemas dalam versi Android agar dapat digunakan banyak pengguna dan dapat diakses kapan pun dan dimanapun.

Hasil penelitian Marzouk (2013) menunjukkan bahwa implementasi pembelajaran Biologi dengan menggunakan AR dengan teknik game dapat menghadirkan pembelajaran yang lebih menyenangkan, kolaboratif, dan atraktif pada pembelajaran tentang anatomi manusia. Penelitian dari Nurdianti (2017) yang menyimpulkan bahwa pembelajaran dengan media AR sangat efektif dengan tingkat pencapaian efektivitas sebesar 89\% terhadap capaian KKM siswa pada konsep ekskresi manusia. Hasil penelitian Morales dan Sanches (2018) tentang penggunaan AR dalam bidang pendidikan mengungkapkan bahwa AR dapat meningkatkan motivasi, hasil belajar dan menciptakan persepsi yang positif terhadap pembelajaran serta memfasilitasi pembelajar untuk memahmi materi lebih baik lagi. Hasil-hasil penelitian yang telah dilakukan sebelumnya menunjukkan bahwa media berbasis AR memiliki potensi yang sangat efektif untuk membantu proses pembelajaran siswa pada pembelajaran Biologi.

\section{METODE}

Penelitian ini menggunakan pendekatan penelitian riset dan pengembangan (R\&D) dengan mengadopsi model Akker (2009) yang terdiri atas empat tahapan, yaitu tahapan penelitian pendahuluan (Preliminary Research), tahapan prototipe (Prototyping Stage), 
tahapan evaluasi sumatif (Summative Evaluation) serta refleksi sistematik dan dokumentasi (Systematic Reflection and Documentation). Aplikasi yang digunakan dalam pengembangan aplikasi ini terdiri atas Unity 3D, Blender, Vuforia, dan Java SDK (Saputro, 2015; Adami, 2016; Ardhianto, 2012; Arifitama, 2017). Implementasi penelitian pengembangan ini dilakukan pada siswa kelas XI SMAN I Kadipaten Kabupaten Majalengka dengan subjek penelitian sebanyak 21 siswa.Instrumen penelitian terdiri atas lembar penilaian ahli, lembar angket, lembar wawancara, dan tes penguasaan konsep sistem saraf. Data dianalisis menggunakan teknik analisis data kualitatif dan kuantitatif.

\section{HASIL DAN PEMBAHASAN}

\section{Hasil}

Penelitian pengembangan ini menggunakan empat tahapan yaitu : (1) tahapan pendahuluan (Preliminari research); (2) tahapan pembuatan prototife (Prototype stage); (3) tahap evaluasi sumatif (Summative Evaluation) dan (4) Tahap refleksi sistematik dan dokumentasi (Systematic Reflection and Documentation). Untuk tahapan (3) dan (4) dilakukan saat produk memasuki fase implementasi lapangan.Berikut adalah tahapan penelitian yang dilakukan sebagai berikut.

\section{Penelitian Pendahuluan (Preliminari Research)}

Untuk mengetahui permasalah yang dihadapi terkait pembelajaran Biologi di SMAN I Kadipaten penulis melakukan penelitian pendahuluan dengan tujuan memperoleh gambaran nyata dari subyek penelitian.Penggalian data pada tahap ini dilakukan melalui kegiatan observasi dan wawancara.Berdasarkan hasil penelitian pendahuluan ini diketahui bahwa penggunaan media pembelajaran Biologi di SMAN I Kadipaten kurang bervariasi dan lebih dominan menggunakan Power Point (Ppt).Penelitian pendahuluan juga menghasilkan temuan bahwa hanya sekitar 35\% siswa yang mampu mencapai KKM pada materi Sistem Koordinasi di tahun ajaran sebelumnya.

\section{Pembuatan Prototife (Prototype Stage)}

Tahapan prototype diawali dengan melakukan analisis kebutuhan (need assessmet) kemudian dilakukan pengembangan prototype media pembelajaran Biologi menggunakan teknologi AR berbasis Android. Pada tahapan ini dilakukan menyusun flowchart, storyboard, desain aplikasi AR berbasis Android, Marker, dan Buku Marker. Berikut adalah flowchart untuk pengembangan prototife media pembelajaran Biologi menggunakan teknologi AR, Marker, dan Buku Marker.

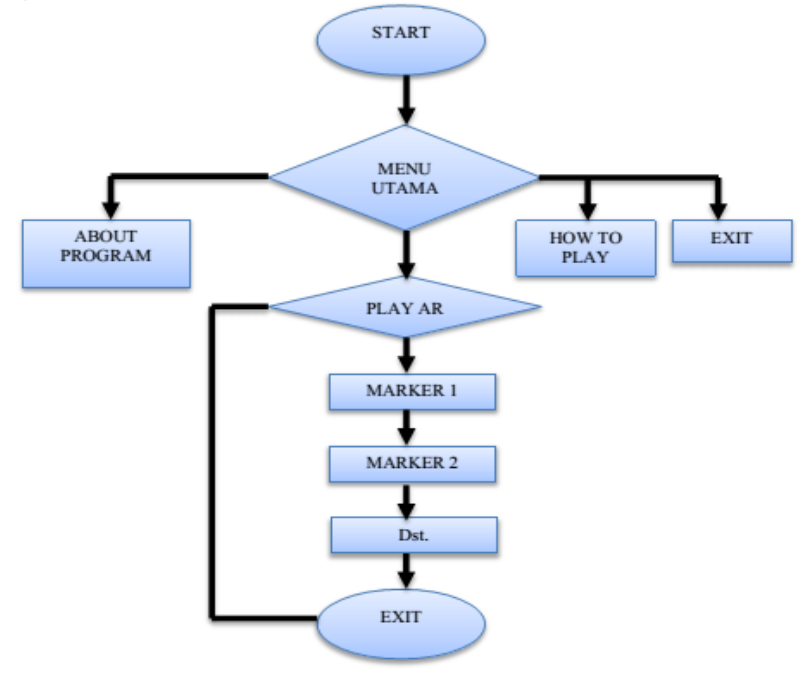


Gambar 1. Flowchart Media Pembelajaran Biologi Menggunakan Teknologi AR

Pada tahapan pembuatan prototife ini dikembangkan juga Marker dan Buku Marker yang berisi materi sub konsep sistem saraf yang dapat dipindai menggunakan aplikasi AR yang telah dikembangkan bersama Markernya.

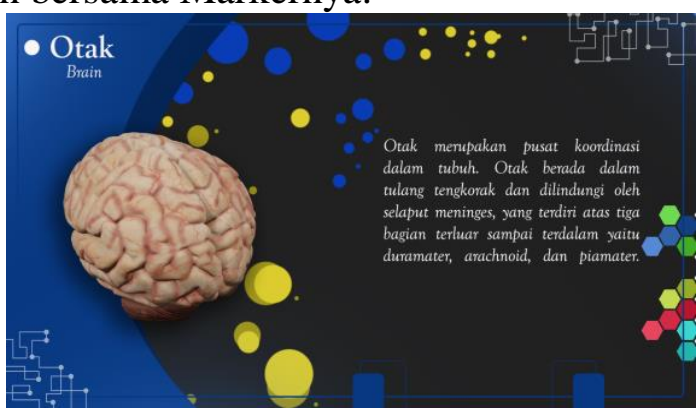

Gambar 2. Marker AR Otak

Marker yang dibuat dikumpulkan dalam Buku Marker, pada bagian Buku Marker selain terdapat Marker yang dapat dipindai menggunakan aplikasi media AR juga tersedia materi tentang sistem saraf dan juga soal latihan untuk dipelajari siswa.

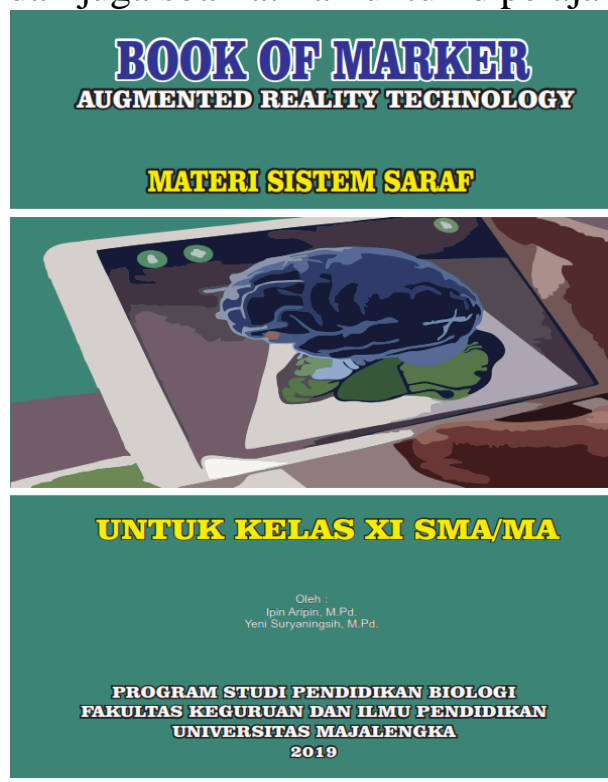

Gambar 3.Buku Marker

Prototife media pembelajaran Biologi menggunakan teknologi AR yang sudah dibuat selanjutnya dilakukan penilaian kelayakan dengan melibatkan tiga ahli yang kompeten dibidang media, konten materi, dan pedagogik.Hasil penilaian ahli terhadap media pembelajaran Biologi menggunakan teknologi AR disajikan pada Tabel 1 berikut.

Tabel 1. Penilaian Kelayakan Media Pembelajaran Biologi Menggunakan Teknologi AR

\begin{tabular}{clcl}
\hline No. & Ahli (Expert) & Penilaian (dalam \%) & \multicolumn{1}{c}{ Keterangan } \\
\hline 1. & Media & 82,33 & Sangat Baik \\
2. & Konten & 80,33 & Baik \\
3. & Pedagogik & 81,86 & Sangat Baik \\
\hline
\end{tabular}


Tabel 1 menunjukkan bahwa menurut penilaian / judgment ahli (expert judgment) prototife media pembelajaran Biologi menggunakan teknologi AR berbasis Android yang telah dikembangkan menenuhi kriteria sebagai media yang layak digunakan (valid).

\section{Evaluasi Sumatif (Summative Evaluation)}

Tahapan evaluasi sumatif merupakan bagian dari implemenetasi penggunaan media secara luas pada pembelajaran Biologi. Evaluasi sumatif dilakukan melalui pemberian tes untuk mengetahui penguasaan konsep siswa pada materi yang dipelajari juga mengetahui tingkat efektivitas dari media pembelajaran Biologi menggunakan teknologi AR yang dikembangkan, selain itu siswa diberi angket untuk mengetahui respon terhadap implementasi penggunaan media berteknologi AR. Hasil tes penguasaan konsep siswa melalui implementasi media pembelajaran Biologi menggunakan teknologi AR dapat dilihat pada Tabel 2 berikut.

Tabel 2. Hasil Tes Penguasaan Konsep

\begin{tabular}{ccccc}
\hline \multicolumn{3}{c}{ Nilai Rataan } & \multirow{2}{*}{ \% Ketuntasan } & \multirow{2}{*}{ Keterangan } \\
\cline { 1 - 3 } Pre-test & Post-test & N-gain & & Efektif \\
\hline 44.19 & 77,33 & 0,59 & $76 \%$ & E
\end{tabular}

Hasil tes penguasaan konsep siswa pada materi sistem saraf pada Tabel 2 di atas menunjukkan bahwa secara umum siswa mengalami peningkatan $\mathrm{N}$-gain dengan kategori sedang dan pencapaian ketuntasan belajar siswa sebesar $76 \%$ termasuk dalam kategori efektif. Adapun hasil angket respon siswa terhadap implementasi media pembelajaran Biologi menggunakan teknologi AR berbasis Android, yaitu sebesar 80,61\% atau dalam rentang baik. Artinya $80,61 \%$ siswa menyatakan bahwa penggunaan media media pembelajaran Biologi menggunakan teknologi AR berbasis Android pada konsep sistem saraf termasuk baik dari segi media, implementasi pembelajaran, interaktivitas, kemenarikan, dan memotivasi siswa untuk belajar.

\section{Refleksi Sistematik dan Dokumentasi (Systematic Reflection and Documentation)}

Tahapan akhir dari pengembangan media pembelajaran Biologi menggunakan teknologi AR, yaitu refleksi sistematik dan dokumentasi (Systematic Reflection and Documentation). Pada tahapan ini berisi refleksi dan dokumentasi terhadap kegiatan penelitian serta bagaimana tampilan dari media yang dikembangkan.Secara umum tahapan implementasi aplikasi media AR diawali dengan sosialisasi penggunaan aplikasi AR pada siswa karena sebelumnya siswa belum pernah menerapkan pembelajaran menggunakan media dengan teknologi AR dalam pembelajaran Biologi. Tahapan berikutnya melakukan implementasi dalam penelitian menggunakan media dengan teknologi AR. Siswa terlebih dahulu diberikan buku Marker dan menginstal aplikasi AR yang telah dikembangkan peneliti. Berikut adalah proses penelitian yang dilakukan.
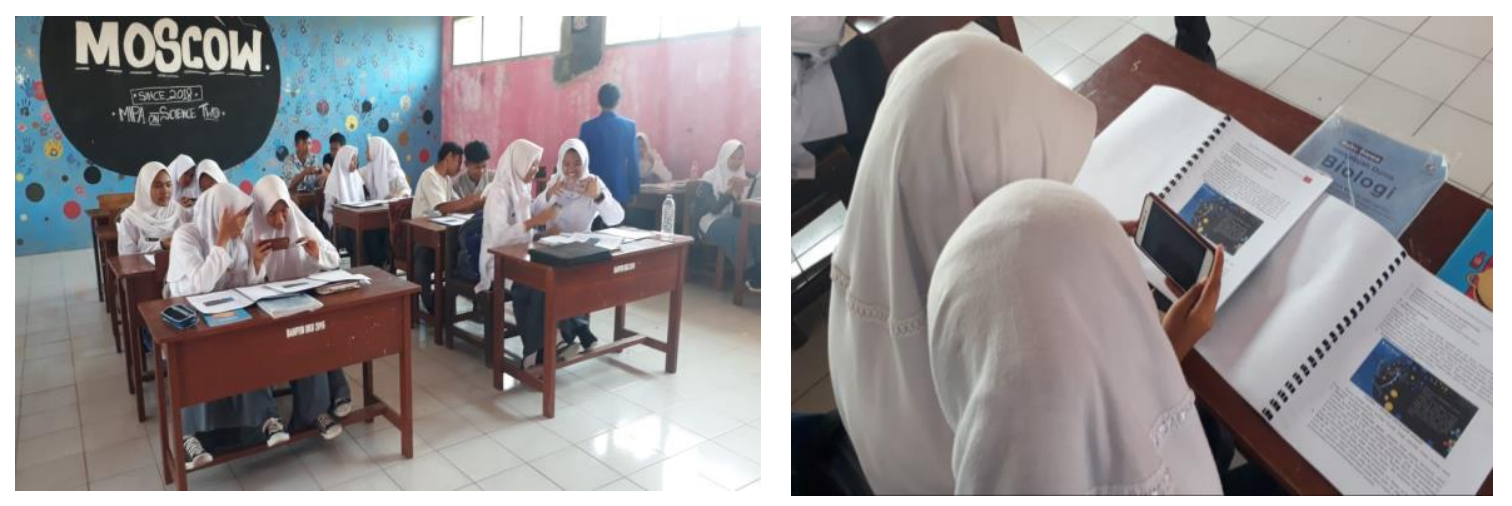

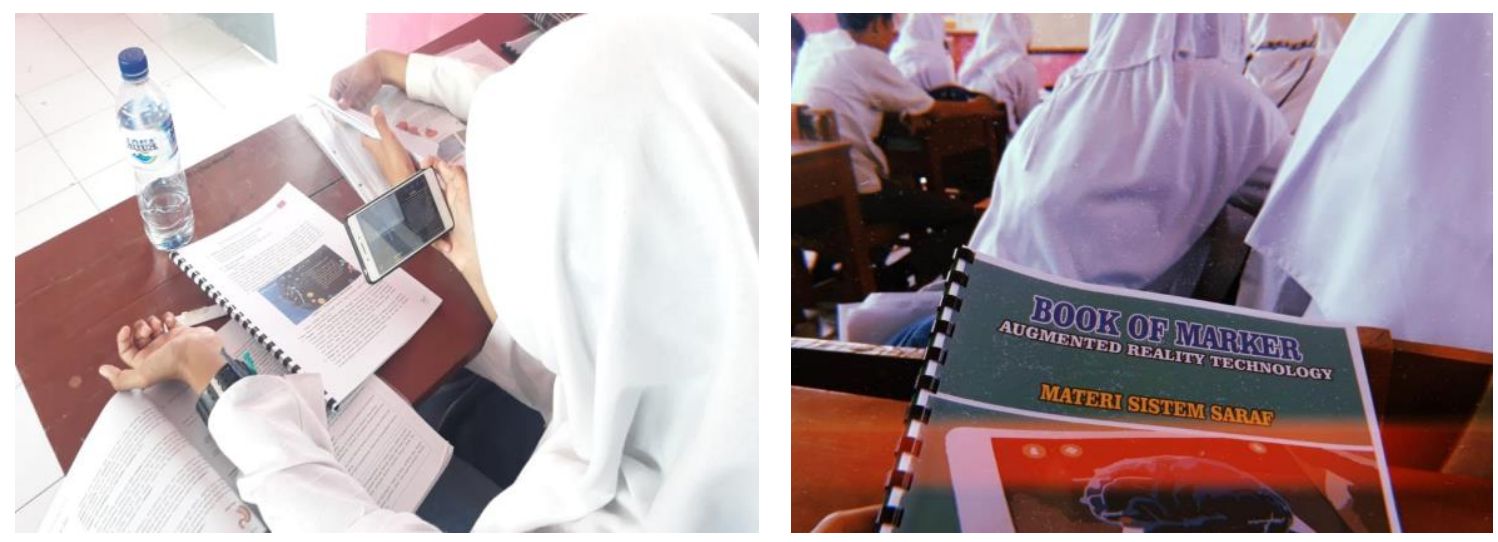

Gambar 4. Implementasi Penggunaan Media AR

Adapun tampilan dari aplikasi media pembelajaran Biologi menggunakan teknologi AR sebagai berikut.

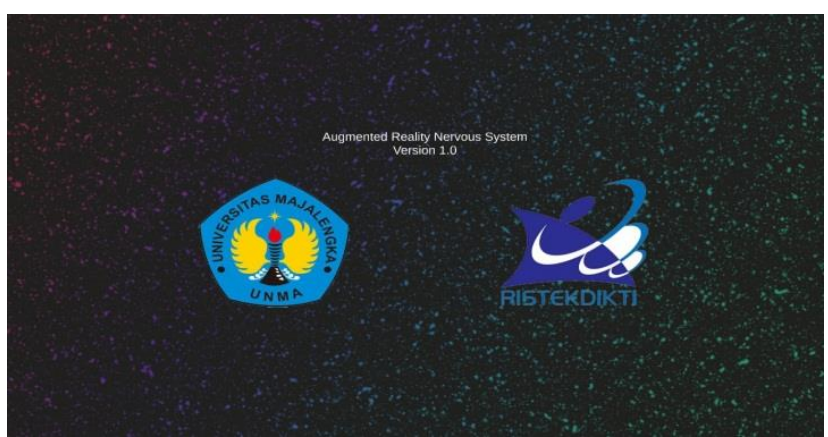

Gambar 5.Tampilan Menu Awal

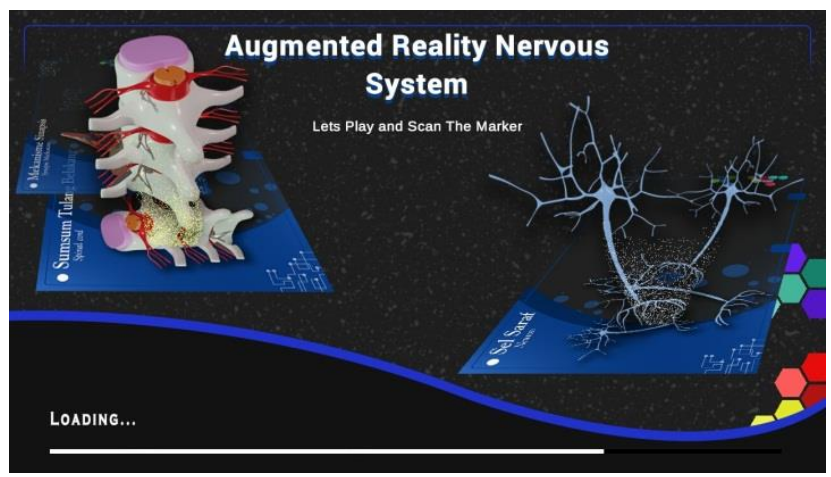

Gambar 6. Menu Loading

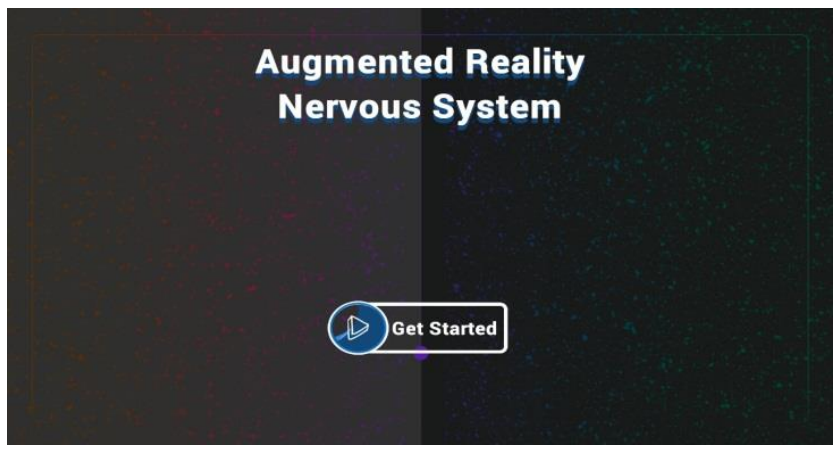

Gambar 7.Menu Start 


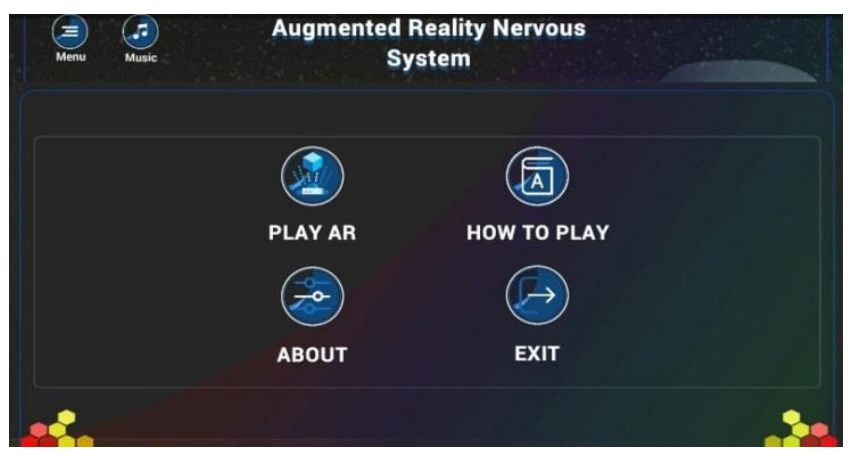

Gambar 8.Tampilan Menu Awal AR

Terdapat empat menu utama yang terdiri atas PLAY AR yang berfungsi untuk memindai Buku Marker, sehingga ketika Buku Marker dipindai akan muncul animasi 3D dari bagian gambar yang dipindai sebagai berikut.

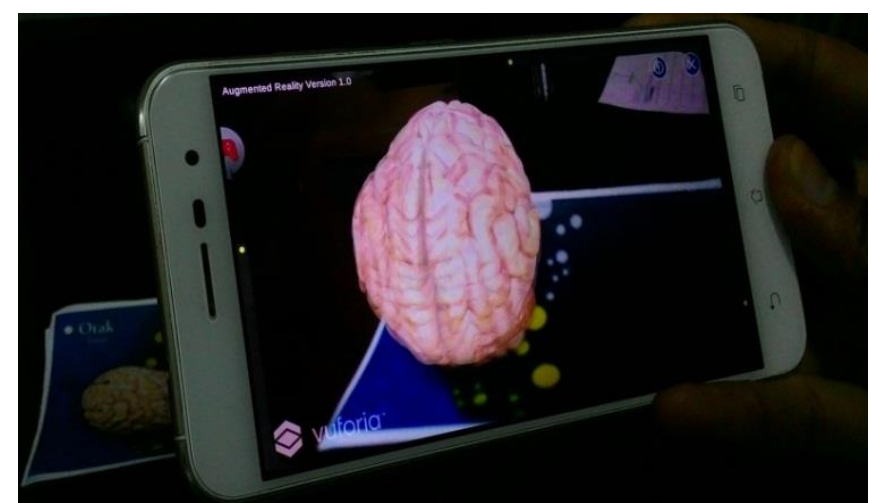

Gambar 9. Tampilan Marker AR 3D Otak Manusia

Saat PLAY AR yang sudah aktif diarahkan pada Buku Marker gambar otak manusia maka akan ditampilkan gambar visualisasi 3D otak manusia beserta dengan keterangan dan animasinya serta materi tambahan pada pojok kanan aplikasi. Selanjutnya terdapat tombol ABOUT yang berisi menu identitas pengembang aplikasi.

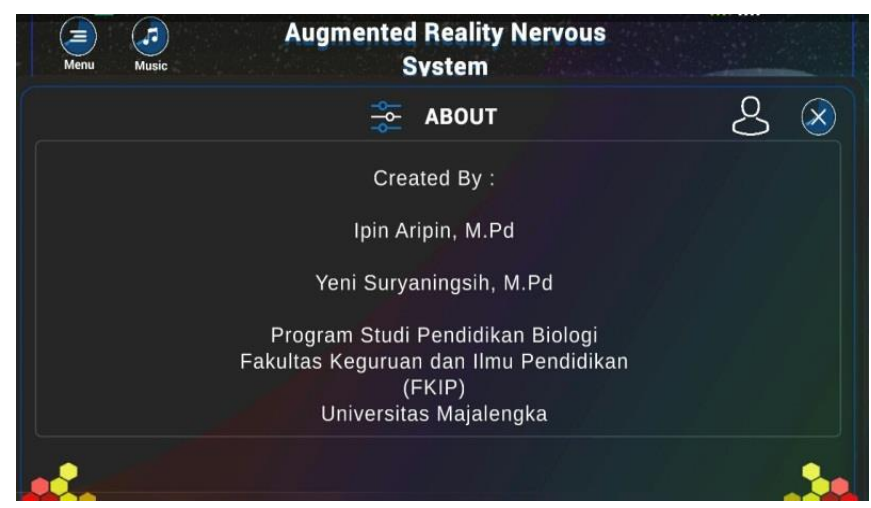

Gambar 10. Tampilan Menu About

\section{Pembahasan}

Pengembangan media media pembelajaran Biologi menggunakan teknologi AR berbasis Android pada penelitian ini diawali dengan studi pendahuluan (Preliminary Research) melalui kegiatan observasi dan wawancara dengan stakeholder terkait untuk memperoleh gambaran awal kondisi nyata di tempat penelitian. Studi pendahuluan ini selanjutnya menjadi dasar dalam melakukan analisis kebutuhan (Need Assesments) dari 
penelitian yang akan dilakukan. Tahapan lanjutan dari penelitian ini adalah melakukan pengembangan prototipe (Prototyping Stage). Hasil analisis kebutuhan dijadikan pijakan untuk pengembangan media yang akan digunakan sebagai solusi yang dihadapi oleh mitra penelitian. Tahap pengembangan prototife dilakukan dengan pembuatan flowchart, storyboard, desain media, desain Marker dan desain Buku Marker.Setelah prototife produk selesai selanjutnya dilakukan uji coba secara terbatas, dan implementasi yang terintegrasi pada tahapan evaluasi sumatif (Summative Evaluation).Ditahap ini produk prototife sudah menjadi produk untuk diimplementasikan dalam skala luas (implementasi lapangan).Dilakukan evaluasi sumatif pada tahap implementasi berupa pemberian tes dan angket untuk mengetahui respon siswa terhadap penggunaan media pembelajaran Biologi menggunakan teknologi AR berbasis Android.

Hasil implementasi penggunaan media AR dalam pembelajaran Biologi konsep sistem saraf menunjukkan bahwa media AR yang dikembangkan tergolong efektif dalam membantu siswa memahami materi konsep sistem saraf.Menurut pendapat siswa salah satu faktor yang membuat siswa tertarik dalam mempelajari materi sistem saraf menggunakan AR ini adalah adanya penggunaan animasi 3D membuat siswa lebih mudah merepresentasikan secara visual struktur dari sistem saraf yang rumit menjadi lebih mudah untuk dideskripsikan secara visual. Menurut Mulyani (2017) representasi visual dalam biologi dapat disajikan dengan menggunakan berbagai bentuk visualisasi, misalnya, photo, gambar, tabel, bagan, diagram, dan lainnya. Penggunaan media AR yang menyajikan representasi visual dalam bentuk 3D tentunya akan memberikan dampak positif terhadap kemampuan siswa dalam memahami konsep yang abstrak. Penggunaan visualisasi 3D melalui media $\mathrm{AR}$ akan menyederhanakan cara penyajian sehingga penjelasan yang diberikan oleh guru akan lebih efektif dan siswa akan lebih mudah memahami materi tersebut.

Media AR selain memiliki keunggulan berupa visualisasi 3D juga ditampilkan berupa animasi.Menurut O'Day (2007: 221) bahwa animasi dapat memberikan pengalaman belajar yang lebih baik dan mengarahkan pada retensi jangka panjang yang lebih besar, dari informasi yang dipelajari.Penelitian Aripin (2011) juga menemukan bahwa penggunaan animasi dinamis dapat meningkatkan retensi siswa terhadap materi yang dipelajarinya lebih lama lagi. Menurut Munir (2015) animasi memiliki beberapa manfaat dalam membantu memfasilitasi pembelajaran, yaitu : (1) menunjukkan objek dengan idea; (2) menjelaskan konsep yang sulit; (3) menjelaskan konsep yang abstrak menjadi konkrit; dan (4) menunjukkan dengan jelas suatu langkah atau prosedur.Sejalan dengan pendapat tersebut Mulyani (2012) mengungkapkan bahwa refresentasi visual pada buku dapat mempengaruhi pemahaman siswa.Penggunaan teknologi AR membuat tampilan visual jauh lebih mendekati aslinya jika dibandingkan representasi visual dari buku ajar yang hanya 2 dimensi.

Tahapan akhir dari penelitian ini adalah refleksi sistematik dan dokumentasi (Systematic Reflection and Documentation) adalah mendeskripsikan bagaimana proses penelitian serta tampilan produk media pembelajaran Biologi menggunakan teknologi Augmented Reality (AR) berbasis Android yang dikembangkan. Tahapan ini juga berisi analisis data dan pelaporan dari tahapan-tahapan penelitian dan pengembangan yang dilakukan dalam penelitian ini.

\section{KESIMPULAN}

Pengembangan media pembelajaran Biologi menggunakan teknologi Augmented Reality (AR) berbasis Android pada penelitian ini terdiri dari empat tahapan, yaitu tahapan penelitian pendahuluan (Preliminary Research), tahapan prototipe (Prototyping Stage), 
tahapan evaluasi sumatif (Summative Evaluation) serta refleksi sistematik dan dokumentasi (Systematic Reflection and Documentation). Hasil penelitian menunjukkan bahwa media yang dikembangkan tergolong layak dan efektif digunakan dalam pembelajaran Biologi konsep sistem saraf dengan tingkat efektivitas sebesar $76 \%$.

\section{DAFTAR PUSTAKA}

Adami, F. Z dan Budihartanti, C. 2016. Penerapan Teknologi Augmented Rality Pada Media Pembelajaran Sistem Pencernaan Berbasis Android. Jurnal Teknik Komputer AMIK BSI, 2(1).

Ardhianto, E. dkk. 2012. Augmented Reality Objek 3 Dimensi dengan Perangkat Artoolkit dan Blender. Jurnal Teknologi Informasi Dinamik, 17(2).

Aripin, I. 2012. Penggunaan Multimedia Interaktif (MMI) untuk Meningkatkan Penguasaan Konsep, Berpikir Kritis, dan Retensi Konsep Sistem Reproduksi Manusia pada Siswa SMA. Jurnal Scientiae Educatia, 1(2).

Aripin, I. 2018. Konsep dan Aplikasi Mobile Learning dalam Pembelajaran Biologi. Jurnal Bio Educatio,3(1). 01-09

Azuma, R. T. 1997. A Survey of Augmented Reality. Presence: Teleoperators and. Virtual Environments 6 (4). 355-385

Irnaningtyas. 2019. Biologi SMA/MA Kelompok Peminatan Matematika dan Ilmu-Ilmu Alam. Jakarta : Erlangga

Kamelia. L. 2015. Perkembangan Teknologi Augmented Reality Sebagai Media Pembelajaran Interaktif Pada Mata Kuliah Kimia Dasar. Journal UIN Sunan Gunung Djati, 9(1)

Marzouk, dkk. 2013. Biology Learning using Augmented Reality and Gaming Techniques. Association of Computer Electronics and Electrical Engineers (ACEE). Tersedia di https://pdfs.semanticscholar.org/.../fed988f50129e12ec4902 Diakses 11 Agustus 2019

Morales, P. T and Garcia, J. M. S. 2018. Use of Augmented Reality In Social Sciences As Educational Resource. Turkish Journal Of Distance Education-Tojde, 19(3)

Mulyani. A. 2012. Sistem Saraf Manusia Dalam Tutorial CBI : Usaha Meningkatkan Keterampilan Generik Sains. Jurnal Scientia Educatia, 1(1).

Mulyani. A. 2013. Penerapan Multimedia-tutorial dalam Pembelajaran Sistem Saraf untuk meningkatkan Keterampilan Berpikir Kritis. Jurnal Scientia Educatia, 2(1).

Mulyani. A. 2017. Penguasaan Mahasiswa Calon Guru Biologi Terhadap Representasi Visual Dalam Botani Phanerogamae. Scientiae Educatia: Jurnal Pendidikan Sains, 6 (1). 15-21

Munir. 2015. Multimedia Konsep dan Aplikasi dalam Pendidikan. Bandung : Alfabeta 
Nurdiati, et al. 2017. Pengembangan Buku Ajar dan Augmented Reality pada Konsep Sistem Eksresi di Sekolah Menengah Atas. UNM Journal of Biological Education, $1(1)$.

O'Day, D. H. 2007. The Value of Animations in Biology Teaching: A Study of LongTerm Memory Retention. CBE-Life Science Education. 26, 217-223

Sanjaya, W. 2013.Strategi Pembelajaran Berorientasi Standar Proses Pendidikan. Jakarta: Kecana

Saputro, R. E. dan Saputra, D. I. E. 2015. Pengembangan Media Pembelajaran Mengenal Organ Pencernaan Manusia Menggunakan Teknologi Augmented Reality. Jurnal Buana Informatika, 6(2).

Sarrab, Mohamed, Laila Elgamel, \& Hamza Aldabbas. 2012. Mobile Learning (MLearning) and Educational Environments. International Journal of Distributed and Parallel System, 3(4). 35.

Vega, J. C. et al. 2017. Using Augmented Reality to Teach and Learn Biochemistry. Journal Biochemistry and Molecular Biology Education, 1(1).

Wang, Y. et al. 2018. Enhancing mechanisms education trough interaction augmented reality simulation. Journal Comput Appl Eng Educ. 